\title{
Linking Visual and Stress Wave Grading of Beech Wood from the Log to the Sawmill Product ${ }^{\dagger}$
}

\author{
Aleš Straže *, Denis Plavčak, Ervin Žveplan and Željko Gorišek
}

Citation: Straže, A.; Plavčak, D.; Žveplan, E.; Gorišek, Ž. Linking Visual and Stress Wave Grading of Beech Wood from the Log to the Sawmill Product. Environ. Sci. Proc. 2021, 3, 65. https://doi.org/10.3390/ IECF2020-08450

Academic Editors: Angela Lo

Monaco, Cate Macinnis-Ng and Om P. Rajora

Published: 16 November 2020

Publisher's Note: MDPI stays neutral with regard to jurisdictional claims in published maps and institutional affiliations.

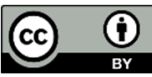

Copyright: (C) 2020 by the authors. Licensee MDPI, Basel, Switzerland. This article is an open access article distributed under the terms and conditions of the Creative Commons Attribution (CC BY) license (http://creativecommons.org/licenses /by/4.0/).

\author{
Biotechnical Faculty, University of Ljubljana, SI 1000 Ljubljana, Slovenia; denis.plavcak@bf.uni-lj.si (D.P.); \\ ervin.zveplan@bf.uni-lj.si (E.Ž.); zeljko.gorisek@bf.uni-lj.si (Ž.G.) \\ * Correspondence: ales.straze@bf.uni-lj.si; Tel.: +386-1-320-3635 \\ † Presented at the 1st International Electronic Conference on Forests - Forests for a Better Future: Sustainabil- \\ ity, Innovation, Interdisciplinarity, 15-30 November 2020; Available online: https://iecf2020.sciforum.net.
}

\begin{abstract}
The quality potential and possibilities of using beech logs and sawn wood was investigated. Twenty-seven beech logs, with a mean diameter of $48 \mathrm{~cm}$, were cut from 10 trees from a Hacquetio epipactidis-Fagetum site in SE Slovenia. The trees were pre-selected according to the national 5-level quality scale for forest stand evaluation, using two trees per class. Beech logs were classified according to the EN 1316-1 and sawn afterwards into unedged boards of $35 \mathrm{~mm}$ nominal thickness. Altogether, 250 boards were visually graded according to the rules of the European Organisation of the Sawmill Industry (EOS). Longitudinal vibration of logs and boards with the determination of stress wave velocity by MTG timber grader was additionally included into the quality assessment. In the case of logs, we confirmed significance of the relationship between visually assessed log quality and stress wave velocity. The stress wave velocity in logs was also related to the stress wave velocity in boards, where it varied considerably, especially for low-graded material. In the case of sawn wood, the relationship between sawn wood grade and stress wave velocity was insignificant. The research confirmed the possibility of presorting of logs, visually or non-destructively, for better classification and utilization of sawn timber.
\end{abstract}

Keywords: beech; quality control; logs; sawnwood; visual assessment; stress wave grading

\section{Introduction}

In general, irregularities and defects reduce the value of roundwood and sawn timber. The identification of defects is important for the quality assessment and grading of logs and is generally done by measuring visible external indicators such as sweep and ovality of the log, injuries caused by biological pests and branch scars [1,2]. Other defects, such as the formation of red heartwood in beech, may be much more difficult to detect by visible external indicators [3]. One of the main defects in roundwood grading is knots, divided into healthy sound and dead knots, where a sound knot, unlike a dead knot, is intergrown with the surrounding wood $[4,5]$.

The common beech (Fagus sylvatica L.) is one of the most important broadleaf species in Europe. The beech is used in various industrial applications such as veneer, plywood, furniture, particleboard, and paper pulp production, but recently there has also been interest in using this wood in the construction industry. There is still a debate about whether to simply peel beech logs or to additionally produce structural sawn timber. For veneer products like LVL, where there is a high degree of homogenization, grading by strength is not particularly important. However, for the production of glued laminated timber (GLT) and cross-laminated timber (CLT), the grading of raw material is of decisive importance [6]. Regardless of how this valuable forest resource is used, information on the appearance, location, and amount of defects is needed [7]. 
Defects in logs, as well as in thicker sawmilling assortments, can be detected using both destructive and non-destructive methods, and only the latter are useful in practice. Visual assessment, as one of the traditional non-destructive techniques, is cheap and only actually available in smaller production capacities, but it is subjective and depends on the human factor [8]. Modern X-ray technologies provide precise measurements and have a high detection capacity, but they are expensive and therefore not suitable for small and medium-sized sawmills [9]. Digital imaging methods based on computer software for analyzing digital images are easier to use and reduce subjectivity when assessing different wood characteristics [10]. Many acoustic methods are also used when using wood for construction purposes, especially for softwoods. Research confirms the positive correlation of the speed of sound with the length and orientation of the fibers and the density of the wood [11,12], while the presence of anomalies in the wood slows down the speed of sound $[13,14]$.

In order to optimize the use of beech logs and sawn wood, and to extend it even further to timber construction in a solid form, this research examines the possibility of monitoring sawn timber quality using non-destructive methods. It will be examined whether the traditional visual classification of logs and sawn wood is related to the speed of sound in these sawmilling assortments.

\section{Material and Methods}

\subsection{Sampling and Visual Grading of Logs}

The study included a sample of ten beech trees from a site of Dinaric (Hac-

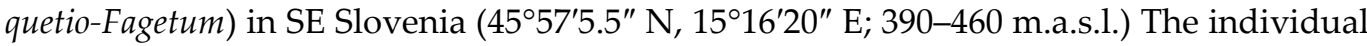
trees differed significantly in quality after visual assessment and were selected on the basis of a national five-grade quality scale. After felling, the trees were cut into logs $(\mathrm{nL}=$ 27), 2.5 to $6.5 \mathrm{~m}$ length (LL), which were first evaluated according to quality [5] in 4 classes (A, B, C, D). To establish the size of defects at individual log, the European standard EN 1310 was used [15].

\subsection{Determining the Stress Wave Velocity in Logs}

The individual log was analyzed after the visual assessment non-destructively by measuring the time of flight of sound along the log. We used a handheld MTG device (MTG-Mechanical Timber Grader; Brookhuis, Enschede, The Netherlands) and placed the device at the front end of the log and excited the log impulsively with a hammer blow (Figure 1). The measured natural frequency of the $\log \left(\mathrm{f}_{\mathrm{L}}\right)$ was used to determine the sound velocity in the longitudinal direction of the $\log (\mathrm{V} \mathrm{L}$; Equation (1)).

$$
v_{L}=2 f_{L} L_{L}
$$

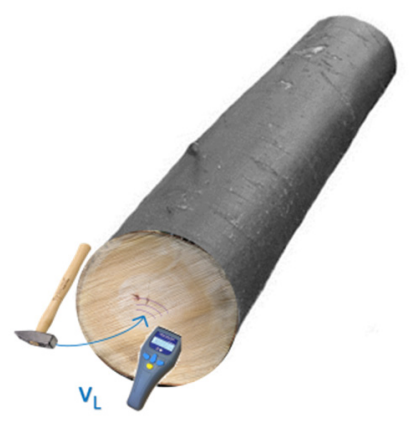

(a)

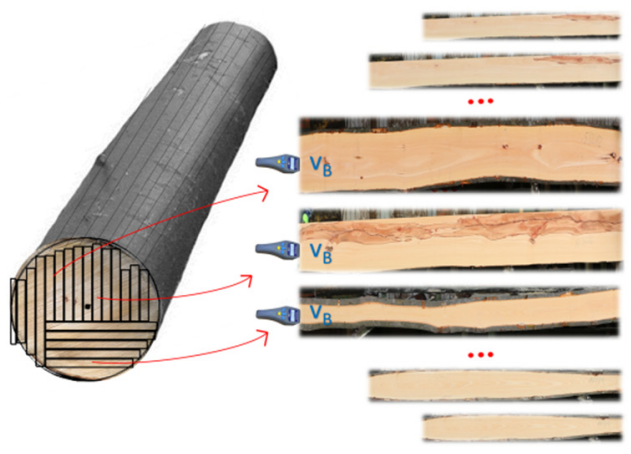

(b)

Figure 1. (a) Determination of the longitudinal stress wave velocity in the $\log (\mathrm{vL})$ by Mechanical Timber Grader (MTG); (b) Cutting of logs into sawn timber with subsequent visual assessment and determination of the longitudinal stress wave velocity in boards (VB). 


\subsection{Sampling and Production of Sawn Timber, Visual Grading and Non-Destructive Testing}

The selected logs were sawn in industrial band sawmill into unedged boards with a nominal thickness of $35 \mathrm{~mm}\left(\mathrm{n}_{\mathrm{s}}=250\right)$, which were marked to allow the traceability of the sawn timber down to the individual log. Immediately after a board was sawn, we measured its width, taking into account half the width of any wane and length of the board (Lв) (Figure 1).

The quality of the sawn boards was evaluated according to the criteria of European Organisation of Sawmill Industry (EOS). According to the grading rules of EOS [16] we divided unedged sawn beech timber into 3 classes (EOS-A, EOS-B, EOS-C).

Finally, we used a handheld MTG device and placed the device at the front end of the sawn board and excited the board impulsively with a hammer blow. The measured natural frequency of the board $\left(f_{B}\right)$ was used to determine the sound velocity in the longitudinal direction of the board ( $\mathrm{vB}$; Equation (2)).

$$
v_{B}=2 f_{B} L_{B}
$$

\section{Results and Discussion}

\subsection{Visual Grading of Logs and Stress Wave Velocity}

The longitudinal stress wave velocity in the logs generally decreased as the visual quality of the logs decreased. Mean values above $3500 \mathrm{~m} / \mathrm{s}$ were confirmed in grades A$\mathrm{C}$ (Class A: $\mathrm{VL}=3715 \mathrm{~m} / \mathrm{s}, \mathrm{CV} \%=10.2$; Class B: $\mathrm{VL}=3615 \mathrm{~m} / \mathrm{s}, \mathrm{CV} \%=13.9 ;$ Class C: $\mathrm{vLC}=$ $3595 \mathrm{~m} / \mathrm{s}, \mathrm{CV} \%=12.8 ; \mathrm{CV} \%$ - Coef. of variation), and significantly lower mean values in grade $\mathrm{D}$ logs $(\mathrm{VLD}=3360 \mathrm{~m} / \mathrm{s} ; \mathrm{CV} \%=9.3)($ Figure 2$)$.

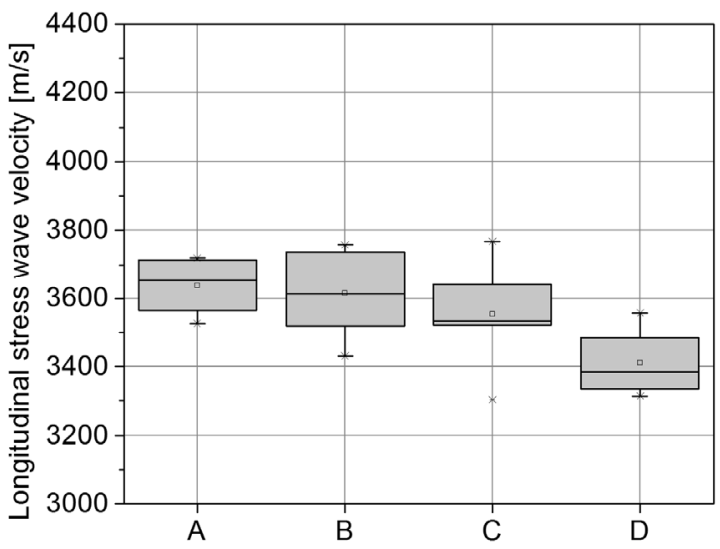

Figure 2. Distribution of longitudinal stress wave velocity $(\mathrm{vL})$ for logs of different quality grades [5].

The results show that the visual grading of roundwood, which is influenced by the diameter, length of the grading assortment, number and size of knots, heart defects, spiral grain and curvature [1], is also related to the velocity of the stress waves in longitudinal direction. However, due to the considerable variability of measurements, we can only reliably distinguish the worst logs (grade D) from higher-quality logs in such non-destructive testing of round timber.

\subsection{Visual Grading of Sawn Wood, Stress Wave Velocity and Dependence on Log Quality}

We confirmed a comparable distribution of the logs by individual classes with the number and proportion of sawn boards in the total selection. The largest share of both logs and boards was in the 2 nd quality class with about $2 / 3$ share. The shares of roundwood and sawn wood of the 1 st and 3rd quality class were up to $1 / 5$, the rest was roundwood of the 4 th quality class (Table 1). Otherwise, sawn boards from the 2 nd 
quality class were similarly represented in the proportion (51.9-66.7\%) in all quality classes of roundwood. Boards of the best quality (EOS-A) were only represented in a significant proportion of quality class A and B logs. With the decline in the quality class of roundwood, the share of boards of the 3rd quality class (EOS-C) increased significantly, up to approx. $40 \%$ share in C- and D-quality class of logs.

Table 1. Proportion and distribution of boards according to quality (EOS-A, EOS-B, EOC-C) [16] within an individual quality class of logs (A, B, C) [5].

\begin{tabular}{|c|c|c|c|c|c|c|c|}
\hline Log Quality & Perc. of Logs (\%) & No. of Boards & Perc. of Boards (\%) & $\begin{array}{c}\text { EOS-A } \\
(\%)\end{array}$ & $\begin{array}{c}\text { EOS-B } \\
(\%)\end{array}$ & $\begin{array}{c}\text { EOS-C } \\
(\%)\end{array}$ & Unsorted $^{1}(\%)$ \\
\hline A & 8.3 & 39 & 15.5 & 15.2 & 66.7 & 15.2 & 3.0 \\
\hline B & 66.7 & 174 & 69.5 & 12.2 & 52.0 & 33.8 & 2.0 \\
\hline $\mathrm{C}$ & 20.8 & 32 & 12.7 & 3.7 & 51.9 & 42.4 & 2.0 \\
\hline $\mathrm{D}$ & 4.2 & 1 & 2.3 & 0.0 & 38.0 & 60.0 & 2.0 \\
\hline Sum & 100.0 & 250 & 100.0 & & & & \\
\hline
\end{tabular}

${ }^{1}$ Boards that did not meet any quality grade.

Similar to the logs, we confirmed the general trend of reducing the stress wave velocity for sawn boards by reducing the quality of the boards. The average sound velocity in boards of the class EOS-A was $3695 \mathrm{~m} / \mathrm{s}(\mathrm{CV} \%=6.9)$, in the class EOS-B $3650 \mathrm{~m} / \mathrm{s}(\mathrm{CV} \%$ $=4.1)$ and in EOS-C $3605 \mathrm{~m} / \mathrm{s}(\mathrm{CV} \%=6.1)$. Otherwise, statistically significant differences between the quality classes of the boards were not confirmed (ANOVA, $p \geq 0.05$ ) (Figure $3 a)$. The measured sound velocities in the boards investigated are generally low, due to wet state testing, as previous research was mostly carried out on sawn beech structural elements made from air dried pre-sorted wood of higher quality [17]. However, research confirms the characteristic relationship between the dynamic mechanical properties, using longitudinal vibration, of wet and air-dried beech sawn timber [18].

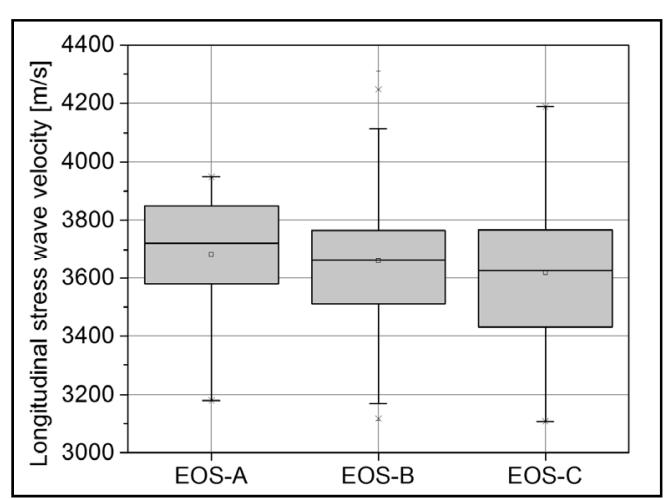

(a)

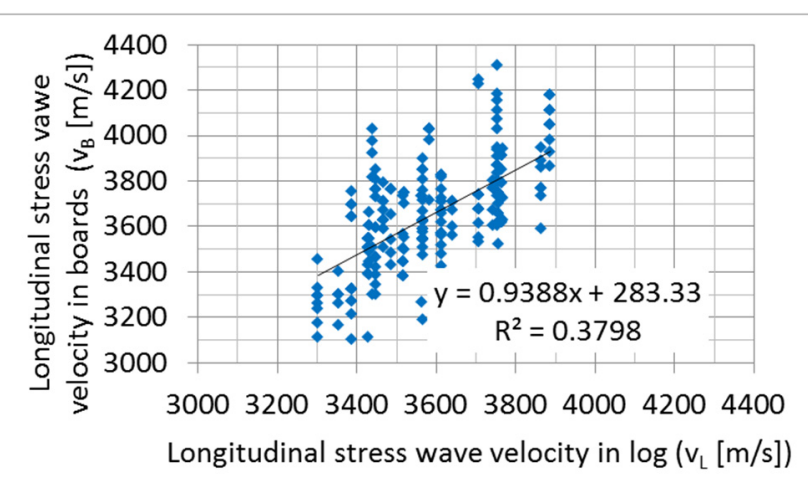

(b)

Figure 3. (a) Distribution of longitudinal stress wave velocity (vв) for boards of different quality grades; (b) Relationship between longitudinal stress wave velocity of logs $(\mathrm{VL})$ and stress wave velocity of sawn boards (Vв).

It turned out that there is a weak positive correlation between the stress wave velocity in logs and the stress wave velocity in boards (Figure $3 b ; R^{2}=0.38$ ). A lower scattering of the stress wave velocity in boards compared to the measured value in logs was confirmed at lower values, i.e., in the case of logs and sawn boards of poorer quality. When investigating the dynamic and mechanical properties of edged beech sawn wood and roundwood, taking into account the radial position in the log and the variation in density, an even stronger relationship was confirmed $\left(\mathrm{R}^{2}=0.69\right)$ [18].

Since practically the entire share of high-quality boards (EOS-A) is obtained from roundwood of quality classes $A$ and $B$, it makes sense to use this roundwood as far as possible for products where a minimal number of anomalies is permitted. In this case, we 
have a small percentage of EOS-C sawn boards that could already be sorted out and can also be used for construction purposes, or where sufficient stiffness and thus the strength of the wood is required. At the same time, the research results also point to the applicability of grade $C$ roundwood, which still reaches a high velocity of stress wave, for products with the required high stiffness and strength.

\section{Conclusions}

The study confirmed the significance of the relationship between the visually assessed beech log quality and stress wave velocity. Due to the measured lower sound velocity along logs of inferior quality, it is possible to pre-sort these logs for better classification and utilization of the sawn timber. The stress wave velocity in logs is also related to the stress wave velocity in boards, which varies considerably, especially with low-graded material. In the case of sawn wood, the relationship between sawn wood grade and stress wave velocity is not significant.

In the future, it would make sense to determine the sound velocity in the transverse direction when pre-sorting logs using NDT. It is also expected that the quality of sawn timber will be significantly influenced by the relative radial position in the log and the dimensions of the sawn timber.

Author Contributions: Conceptualization, A.S. and Ž.G.; methodology, A.S. and Ž.G.; formal analysis, D.P. and E.Ž.; writing-original draft preparation, A.S.; writing-review and editing, A.S., Ž.G., D.P. and E.Ž.; visualization, D.P. and. E.Ž.; supervision, Ž.G. All authors have read and agreed to the published version of the manuscript.

Funding: This research was funded by Ministry of Agriculture, Forestry and Food and Slovenian Research Agency as a part of project "Rational use of hardwoods within a focus on beech wood" (V4-1419) within the research program P4-0015 (Wood and lignocellulosic composites).

Acknowledgments: The authors would like to thank the colleagues of the V4-1419 project for the collection and exchange of data and for the mutual support and cooperation. We would also like to thank Tomaž Pazlar and the National Building and Civil Engineering Institute for the use of the MTG timber grader. Special thanks go to the technical assistants Luka Krže, Drago Vidic, for organizing the field work.

Conflicts of Interest: The authors declare no conflict of interest. The funders had no role in the design of the study; in the collection, analyses, or interpretation of data; in the writing of the manuscript, or in the decision to publish the results.

\section{References}

1. Marenče, J.; Šega, B.; Gornik Bučar, D. Monitoring the Quality and Quantity of Beechwood from Tree to Sawmill Product. Croat. J. For. Eng. 2020, 41, 119-128, doi:10.5552/crojfe.2020.613.

2. Torkaman, J.; Vaziri, M.; Sandberg, D.; Limae, S.M. Relationship between branch-scar parameters and knot features of oriental beech (Fagus orientalis Libsky). Wood Mater. Sci. Eng. 2018, 13, 1-4, doi:10.1080/17480272.2018.1424731.

3. Knoke, T. Predicting red heartwood formation in beech trees (Fagus sylvatica L.). Ecol. Model. 2003, 169, $292-312$.

4. Karaszewski, Z.; Bembenek, M.; Mederski, P.S.; Szczepanska-Alvarez, A.; Byczkowski, R.; Kozlowska, A.; Mischnowicz, K.; Przytula, W. Identifying beech round wood quality-Distributions and the influence of defects on grading. Drewno 2013, 56, 39-54, doi:10.12841/wood.1644-3985.041.03.

5. European Committee for Standardization. EN 1316-1 Hardwood Round Timber-Qualitative Classification-Part 1: Oak and Beech; CEN: Brussels, Belgium, 2010; p. 9.

6. Erhart, T.; Fink, G.; Steiger, R.; Frangi, A. Strength gradig of European beech lamellas for the production of GLT and CLT. In Proceedings of the International Network on Timber Engineering Research-Meeting 49, Graz, Austria, 16-19 August 2016; pp. 29-42.

7. Gorišek, Ž.; Plačak, D.; Gornik Bučar, D.; Merela, M.; Čufar, K.; Straže, A. Physical and mechanical properties of green and dry wood in beech stems blown down in ice storm. Acta Silvae Et Ligni 2017, 112, 7-20, doi:10.20315/ASetL.112.2.

8. Račko, V. Verify the accuracy of estimation the model between dimensional characteristics of branch scar and the location of the knot in the beech trunk. For. Wood Technol. 2013, 84, 60-65.

9. Longuetaud, F.; Mothe, F.; Kerautret, B.; Krähenbühl, A.; Hory, L.; Leban, J.M.; Debled-Rennesson, I. Automatic knot detection and measurements from X-ray CT images of wood. A review and validation of an improved algorithm on softwood samples. Comput. Electron. Agric. 2012, 85, 77-89. 
10. Sioma, A. Assessment of wood surface defects based on 3D image analysis. Wood Res. 2015, 60, 339-350.

11. Wang, X.; Carter, P.; Ross, R.J.; Brashaw, B.K. Acoustic assessment of wood quality of raw materials-a path to increased profitability. For. Prod. J. 2007, 57, 6-14.

12. Ross, R. Nondestructive Evaluation of Wood; Forest Producty Laboratory: Madison, WI, USA, 2015; p. 169.

13. Krajnc, L.; Kadunc, A.; Straže, A. The use of ultrasound velocity and damping for the detection of internal structural defects in standing trees of European beech and Norway spruce. Holzforschung 2019, 73, 807-836, doi:10.1515/hf-2018-0245.

14. Carter, P.; Wang, X.; Ross, R.J. Field application of processor head acoustic technology in forest harvest operations. In Proceedings of the 18th International Nondestructive Testing and Evaluation of Wood Symposium, Madsion, WI, USA, 24-27 September 2013; pp. 7-14.

15. European Committee for Standardization. EN 1310 Round and Sawn Timber-Method of Measurement of Features; CEN: Brussels, Belgium, 1997; p. 22.

16. European Organization for the Sawmill Industry. Grading Rules for Unedged Lumber-Beech; HolzAbsatzFonds: Bonn, Germany, 2014.

17. Frühwald, K.; Schickhofer, G. Strength grading of hardwoods. In Proceedings of the 8th World Conference on Timber Engineering, Lahti, Finland, 14-17 June 2004; pp. 675-679.

18. Rais, A.; Pretzsch, H.; Kuilen, J.W.G. European beech log and lumber grading in wet and dry conditions using longitudinal vibration. Holzforschung 2020, 74, 939-947, doi:10.1515/hf-2019-0227. 